\title{
Body size, weight change, fat distribution and breast cancer risk in Hispanic and non-Hispanic white women
}

\author{
Martha L. Slattery $\cdot$ Carol Sweeney $\cdot$ Sandra Edwards · \\ Jennifer Herrick · Kathy Baumgartner · \\ Roger Wolff - Maureen Murtaugh · Richard Baumgartner • \\ Anna Giuliano $\cdot$ Tim Byers
}

Published online: 22 May 2007

(C) Springer Science+Business Media B.V. 2007

\section{Erratum to: Breast Cancer Res Treat DOI 10.1007/s10549-006-9292-y}

We regret to inform you that we have identified an error in the data on height reported in Table 5 of our manuscript "Body size, weight change, fat distribution and breast cancer risk in Hispanic and non-Hispanic white women", printed in Breast Cancer Research and Treatment. The corrected data is presented below. We erroneously reported that Hispanic post-menopausal women with very short

The online version of the original article can be found under doi: 10.1007/s10549-006-9292-y

M. L. Slattery $(\bowtie) \cdot$ C. Sweeney $\cdot$ S. Edwards .

J. Herrick · R. Wolff · M. Murtaugh

Health Research Center, University of Utah, Salt Lake City,

UT 84117, USA

e-mail: jmslatter@hrc.utah.edu

\section{K. Baumgartner $\cdot$ R. Baumgartner}

Department of Internal Medicine and the Cancer Research and

Treatment Center Epidemiology and Cancer Prevention

Program, University of New Mexico Health Science Center,

Albuquerque, New Mexico

\section{A. Giuliano}

University of Arizona, Tucson, AZ, USA

\section{T. Byers}

University of Colorado School of Medicine, Denver, CL, USA

Present Address:

K. Baumgartner $\cdot$ R. Baumgartner

University of Louisville, Louisville, KT, USA

Present Address:

A. Giuliano

Moffitt Cancer Center, Tampa, FL, USA
Table 5 Association of breast cancer with body size in Hispanics by genetic admixture

\begin{tabular}{ccclll}
\hline \% Membership & \multicolumn{2}{l}{ Pre/Peri Menopausal } & & \multicolumn{2}{l}{ Post-menopausal } \\
\cline { 2 - 3 } population one & $<61.7 \%$ & $>61.7 \%$ & & $<61.7 \%$ & $>61.7 \%$ \\
& OR $(95 \%$ & OR $(95 \%$ & & OR $(95 \%$ & OR $(95 \%$ \\
& CI) & CI $)$ & CI $)$ & CI $)$ \\
\hline Height (m) & & & & \\
$\leq 1.55$ & $0.72(0.33$, & $1.40(0.69$, & $0.89(0.51$, & $1.96(1.06$, \\
& $1.57)$ & $2.85)$ & $1.56)$ & $3.65)$ \\
$1.56-1.60$ & 1.00 & 1.00 & 1.00 & 1.00 \\
$>1.60$ & $1.07(0.53$, & $0.70(0.34$, & $1.55(0.88$, & $1.60(0.82$, \\
& $2.16)$ & $1.43)$ & $2.74)$ & $3.14)$ \\
\hline
\end{tabular}

stature were at reduced breast cancer risk with greater American Indian ancestry when in factor these women are at increased risk. All other numbers and $p$ values were correctly published. 